Marquette University

e-Publications@Marquette

$12-2016$

\title{
A Replication and Extension of the PEERS $\circledast$ for Young Adults Social Skills Intervention: Examining Effects on Social Skills and Social Anxiety in Young Adults with Autism Spectrum Disorder
}

\author{
Alana J. McVey \\ Marquette University \\ Bridget Dolan \\ Marquette University, bridget.dolan@marquette.edu \\ Kirsten S. Willar \\ Marquette University \\ Sheryl Pleiss \\ University of Minnesota \\ Jeffrey S. Karst \\ Marquette University, jeffrey.karst@marquette.edu
}

See next page for additional authors

Follow this and additional works at: https://epublications.marquette.edu/psych_fac

Part of the Psychology Commons

\section{Recommended Citation}

McVey, Alana J.; Dolan, Bridget; Willar, Kirsten S.; Pleiss, Sheryl; Karst, Jeffrey S.; Casnar, Christina L.; Caiozzo, Christina; Vogt, Elisabeth M.; Gordon, Nakia; and Van Hecke, Amy V., "A Replication and Extension of the PEERS ${ }^{\circledR}$ for Young Adults Social Skills Intervention: Examining Effects on Social Skills and Social Anxiety in Young Adults with Autism Spectrum Disorder" (2016). Psychology Faculty Research and Publications. 209.

https://epublications.marquette.edu/psych_fac/209 


\section{Authors}

Alana J. McVey, Bridget Dolan, Kirsten S. Willar, Sheryl Pleiss, Jeffrey S. Karst, Christina L. Casnar, Christina Caiozzo, Elisabeth M. Vogt, Nakia Gordon, and Amy V. Van Hecke 


\title{
A Replication and Extension of the PEERS $®$ for Young Adults Social Skills Intervention: Examining Effects on Social Skills and Social Anxiety in Young Adults with Autism Spectrum Disorder
}

\author{
Alana J. McVey \\ Psychology Department, Marquette University \\ Milwaukee, WI \\ Bridget K. Dolan \\ Psychology Department, Marquette University \\ Milwaukee, WI \\ Kirsten S. Willar \\ Psychology Department, Marquette University \\ Milwaukee, WI \\ Children's Hospital of Colorado, \\ Aurora, CO
}


NOT THE PUBLISHED VERSION; this is the author's final, peer-reviewed manuscript. The published version may be accessed by following the link in the citation at the bottom of the page.

\author{
Sheryl Pleiss \\ Children's Hospital of Colorado, \\ Aurora, CO \\ University of Minnesota, \\ Minneapolis, $M N$ \\ Jeffrey S. Karst \\ Psychology Department, Marquette University \\ Milwaukee, WI \\ Children's Hospital of Wisconsin, \\ Milwaukee, WI \\ Christina L. Casnar \\ University of Wisconsin - Milwaukee, \\ Milwaukee, WI \\ Christina Caiozzo \\ Psychology Department, Marquette University \\ Milwaukee, WI \\ Elisabeth M. Vogt \\ Psychology Department, Marquette University \\ Milwaukee, WI \\ Nakia S. Gordon \\ Psychology Department, Marquette University \\ Milwaukee, WI \\ Amy Vaughan Van Hecke \\ Psychology Department, Marquette University \\ Milwaukee, WI
}

\begin{abstract}
Young adults with ASD experience difficulties with social skills, empathy, loneliness, and social anxiety. One intervention, PEERS® for Young Adults, shows promise in addressing these challenges. The present study replicated and extended the original study by recruiting a larger sample $(N=56)$, employing a gold standard ASD assessment tool, and examining changes in social anxiety utilizing a randomized controlled trial design.


Results indicated improvements in social responsiveness (SSIS-RS SS, $p=.006$ and $\mathrm{CPB}, p=.005$; SRS, $p=.004$ ), PEERS ${ }^{\circ}$ knowledge (TYASSK, $p=.001$ ), empathy (EQ, $p=.044)$, direct interactions (QSQ-YA, $p=.059$ ), and social anxiety (LSAS-SR, $p=.019$ ). Findings demonstrate further empirical support for the intervention for individuals with ASD.

Keywords: Autism, ASD, Social anxiety, Young adulthood, Intervention, Social skills

\section{Introduction}

The prevalence of autism spectrum disorder (ASD) continues to rise steadily. According to the Centers for Disease Control and Prevention, about one in 45 children in the United States carries a diagnosis of ASD (Zablotsky et al. 2015). Although predominantly conceptualized as a childhood disorder, the persistence of deficits and lack of efficacious treatments for ASD lead to striking difficulties that continue well into adulthood (Seltzer et al. 2004; Warren et al. 2011). This paper will provide an overview of ASD in young adulthood, focusing specifically on social skills deficits, empathy, loneliness, and social anxiety. The current literature on interventions for young adults (YAs) will then be described. These issues will be covered in light of the current study, which examined the behavioral effects of $P E E R S \circledR$ for Young Adults (Gantman et al. 2012), a relationship-development intervention for YAs with ASD.

\section{ASD in Young Adulthood}

Many of the social skills deficits common to children and adolescents with ASD are, unsurprisingly, also rife among YAs on the spectrum. Individuals with ASD often struggle with social cognition, such as theory of mind, and may have difficulty initiating or maintaining social interaction and reading social cues (Buitelaar et al. 1999). Social skills deficits may present as limited verbal and nonverbal communication, lack of eye contact, limited reciprocal speech, and lack of insight (White et al. 2007). Limited social contact with other YAs may play a role. Compared with adolescents, most of whom are in high school, YAs may be in a variety of settings including: college, vocational training, or the workforce; they may be living autonomously with or without parental support, in an independent living facility, or at home with their parents (Gantman et al. 2012). 
Research has indicated, however, that the largest proportion of YAs with ASD live at home with their parents, are unemployed or underemployed, and are not in higher education (Howlin 2000). Many YAs with ASD continue to depend heavily on parents or primary caregivers (Barnhill 2007; Farley et al. 2009; Howlin et al. 2004). Unfortunately, this also means that these YAs with ASD often experience fewer interactions with peers than typically developing (TD) YAs (Gantman et al. 2012), which further hinders social skills development. Social skills challenges have a negative impact on the development of friendships and romantic relationships, which in turn, further negatively impacts the autonomy of individuals with ASD (Barry et al. 2009).

\section{Empathy and Loneliness in ASD}

Individuals with ASD face difficulties with broader relational constructs including empathy and loneliness. Empathy, or the ability to understand the emotional state of others, has long been recognized as a challenge for individuals with ASD (Dziobek et al. 2008; Golan and Baron-Cohen 2006; Kennett 2002). These difficulties are often linked to an impaired ability to read, comprehend, and produce outward expressions of emotion that may offer insight about another's experience (Golan and Baron-Cohen 2006). These challenges may limit the likelihood of individuals with ASD developing successful, high quality social relationships, as has been shown among individuals with behavioral disorders in general (Schonert-Reichl 1993).

Although less studied among YAs with ASD than youth, feelings of loneliness play an important role in the development of YAs with ASD (Bauminger et al. 2003; Locke et al. 2010; White and RobersonNay 2009). Among high functioning children with ASD, Bauminger et al. (2003) found they experienced higher levels of loneliness than their TD peers, and were less able to associate that loneliness with the absence of social interactions. Similarly, Locke et al. (2010) found that adolescents with ASD experienced higher levels of both social and emotional loneliness, poorer social relationships, and lower social status than their TD peers. Certainly, as children with ASD progress into adolescence, social deficits may become more pronounced as the social environment becomes more complex. Friendships that YAs with 
ASD forge may also be less positive than those among TD adults. Baron-Cohen and Wheelwright (2003) found that individuals with ASD had friendships that were less close, empathetic, supportive, and important than those of TD individuals. Loneliness among individuals with ASD may be moderated by symptoms of anxiety. White and Roberson-Nay (2009) found that children and adolescents with ASD who demonstrated higher levels of loneliness also showed higher levels of anxiety, via self- and parent-report measures. The presence of anxiety among individuals with ASD is an important consideration when evaluating this population, as anxious symptoms may exacerbate social difficulties in ASD, such as friendship development.

\section{Interventions for Young Adults with ASD}

Because of the long-term impact of social skills deficits among individuals with ASD, it is clear that development of such skills is imperative for YAs on the spectrum. However, very few social skills programs targeting the skills deficits common in ASD extend into young adulthood. In a recent meta-analysis, the Cochrane Collaboration did not uncover any evidence-based social skills for individuals over 17 years (Reichow et al. 2013). In their review, Palmen, Didden, and Lang (2012) identified eight interventions targeting social interaction skills, only two of which were deemed conclusive. These two studies utilized a small-group format, demonstrations of appropriate skills, and behavioral rehearsals wherein participants practiced the skills and received feedback (Dotson et al. 2010; Palmen et al. 2008). Dotson et al. (2010) found that four of their five participants achieved mastery of the three conversation skills taught. Palmen et al. (2008) found that participants demonstrated significant improvements in question asking and response efficiency within their sample. Although of value to the field, these interventions were flawed in a number of ways. Both studies focused exclusively on speaking skills even though social interaction involves a great deal more than conversational acuity. Both studies had very small sample sizes ( $N=5$ and $N=9$, respectively). The review by Palmen et al. (2012) highlighted that, while some social skills interventions for YAs with ASD have been developed and examined, the vast majority are not methodologically sound, and those with methodological rigor are very limited in scope. 
NOT THE PUBLISHED VERSION; this is the author's final, peer-reviewed manuscript. The published version may be accessed by following the link in the citation at the bottom of the page.

\section{The PEERS $®$ Intervention}

One recently developed intervention for individuals with ASD attempts to address these issues. The Program for the Education and Enrichment of Relational Skills (PEERS®) is a 14-week social skills intervention for adolescents with ASD that targets making and keeping

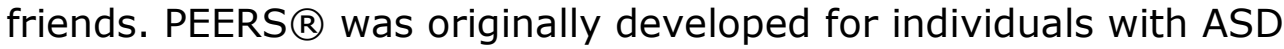
aged 11-16 and has been shown to be efficacious for improving social skills and friendships among individuals in this age group (Frankel et al. 2010; Laugeson et al. 2009). The intervention focuses on smallgroup instruction of didactic material, role-plays, behavioral rehearsal, coaching, and weekly homework assignments for social skills practice. Parents receive complementary information delivered simultaneous to, but separate from, the adolescents (Laugeson et al. 2009). This format allows for parent facilitation of learning and socialization practice, and also group discussion of successes and challenges the parents experience during the implementation of the new skills. The content of the intervention includes concretized rules for proper social etiquette in important social situations for adolescents (Laugeson et al. 2009). Specific skills include: conversation, peer entry and exit, developing friendship networks, teasing, bullying, arguments, good sportsmanship, host behavior, and changing a bad reputation (Laugeson et al. 2009). PEERS $®$ for adolescents has been replicated outside of its University of California, Los Angeles (UCLA) site of development by two groups (Schohl et al. 2014; Yoo et al. 2014), and its efficacy has been demonstrated at both sites as well.

Importantly, PEERS $®$ has been adapted and manualized for YAs aged 18-23 (PEERS® for Young Adults; Gantman et al. 2012). Young adulthood is a unique period of development, in particular because as individuals enter young adulthood, they begin to cultivate more autonomy, in the formation and maintenance of social relationships

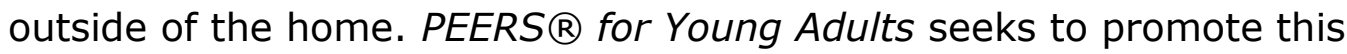
development of autonomy within YAs with ASD through the cultivation of social skills. There are two main differences in the YA version

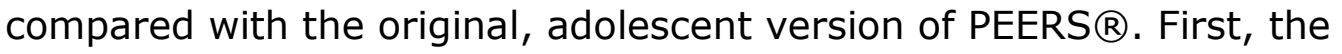
YA version includes a reconfiguration of the original 14 modules to highlight the varying experiences of YAs. Second, three additional modules pertaining specifically to dating etiquette were added, as 
these skills are more commonly relied upon in young adulthood than in adolescence for individuals with ASD.

Upon examination of the efficacy of the intervention, the developers have shown PEERS $\&$ for Young Adults to be efficacious (Gantman et al. 2012). PEERS® for Young Adults was found to improve parent-reported social skills behavior and self-reported social skills knowledge, while also increasing the number of direct social interactions of YAs with ASD. It was also shown to have a positive impact on empathy and loneliness among this population. Although these findings were recently replicated within the site of development at UCLA (Laugeson et al. 2015), they have not yet been independently replicated outside of that site. Additionally, the data from both the original study and the replication were comprised of small sample sizes ( $N=17, N=22$, respectively). Furthermore, both Gantman et al. (2012) and Laugeson et al. (2015) utilized the Autism Quotient (Baron-Cohen et al. 2001) and a community diagnosis of ASD to confirm the diagnostic status of their participants, rather than employing a gold standard assessment measure.

\section{Social Anxiety in ASD}

Anxiety may affect symptom presentation and outcome in ASD. Anxiety has been found to occur in about $40 \%$ of individuals with ASD, with ranges between $11 \%$ and $84 \%$ in community and clinic-referred samples (van Steensel et al. 2011; White et al. 2009). Social anxiety, and/or social phobia, in particular, may compound social skills deficits. According to the DSM-IV-TR, social phobia is differentiated from social anxiety disorder by marked distress when performing in front of others (American Psychiatric Association 2000), though these diagnoses were merged for the DSM-5 (American Psychiatric Association 2013). For the purposes of the present study, "social anxiety" is considered the umbrella term that encompasses both social anxiety and social phobia, while "social phobia" is reserved for diagnoses of that disorder made under the DSM-IV-TR. Between 17 and $22 \%$ of children and adolescents with ASD have been found to exhibit co-occurring social anxiety (van Steensel et al. 2011). For adults, Lever and Geurts (2016), found that $21.7 \%$ of their sample of young adults with ASD met DSM-IV-TR criteria for social phobia, while Maddox and White 
(2015) found that $50 \%$ of their adult participants met criteria for social anxiety disorder (with $21 \%$ showing mild, $29 \%$ moderate, and $21 \%$ severe levels of social anxiety). Bellini (2006) demonstrated empirical support for a developmental pathways model of social anxiety and ASD that links temperament, physiological arousal, social functioning, and anxiety. This model proposes that individuals with ASD exhibit a temperament of high physiological arousal. Later in life, this temperament style leads these individuals to be more likely to withdraw from social situations. As a result, social skills go unpracticed and are underdeveloped. As time goes on, social interactions become more challenging and are often more negative due to social skills deficits, which in turn leads to increased symptoms of social anxiety. Social anxiety only perpetuates the cycle by increasing already high levels of social withdrawal. Assuming this pattern of increased social anxiety and decreased social interaction continues, it makes sense that the prevalence of social anxiety among YAs with ASD would be similar to, if not greater than, that of adolescents with ASD.

The developers of the PEERS $®$ for Young Adults intervention did not examine changes in social anxiety or social phobia within their sample. However, research has demonstrated that the PEERS ${ }^{\circledR}$ intervention for adolescents with ASD has a positive impact on social anxiety symptoms (Schohl et al. 2014). Based on the theory proposed by Bellini (2006), it is expected that young adults who participate in PEERS ${ }^{\circledR}$ for Young Adults will gain social skills that will enable them to feel more confident in social situations, leading to more positive interactions with peers and less fear and avoidance of these social interactions. Further, it is expected that the in-session role-plays and behavioral rehearsals with same-aged peers will function somewhat like an exposure-based anxiety treatment. However, it is not suspected that $P E E R S \circledR$ for Young Adults will show the same marked improvement in social anxiety symptoms as well-established cognitive behavioral therapy (CBT) interventions that are targeted specifically to address these difficulties.

\section{Summary and Aims of the Current Study}

The current study was a replication and extension of the PEERS $®$ for Young Adults intervention. The program was conducted in

Journal of Autism and Developmental Disorders, Vol 46, No. 12 (December 2016): pg. 3739-3754. DOI. This article is (C) Springer and permission has been granted for this version to appear in e-Publications@Marquette. Springer does not grant permission for this article to be further copied/distributed or hosted elsewhere without the express permission from Springer. 
the manner described by the researchers at UCLA, employing a randomized controlled trail, and utilizing the PEERS® for Young Adults manual (Laugeson in press). Sessions were conducted at the same timing and rate as at the site of development, that is, one 90-min session per week for 16 weeks. The current study extends the first PEERS $®$ for Young Adults study in three important ways. First, a larger sample size was recruited. Specifically, a total of 57 YAs with ASD were recruited, who were randomly assigned to experimental or waitlist groups, in the manner conducted by Gantman et al. (2012). Participants ranged in age from 17 to 28. Second, more stringent diagnostic criteria (i.e., the Autism Diagnostic Observation Schedule, Lord et al. 2000) was used for screening the YAs who were recruited to participate. Third, the current study examined the effects of the social skills intervention on levels of social anxiety, which were not explored in the Gantman et al. (2012) or Laugeson et al. (2015) study.

The first and primary aim of the present study was to replicate the Gantman et al. (2012) findings, as pertains to PEERS $®$ ' effects on social skills knowledge, ASD symptoms, empathy, loneliness, and social contacts. Based on the original findings, it was predicted that

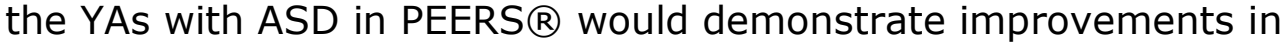
these areas over time. The second aim of the present study was to extend the findings of Gantman et al. (2012) by examining the effect of PEERS $\&$ participation on social anxiety. Based on the theory previously discussed, wherein social skills deficits lead to increased social anxiety (Bellini 2006), it was hypothesized that the YAs with ASD in the experimental group would report, on average, lower levels of social anxiety after receiving the intervention.

\section{Method}

\section{Participants}

Fifty-six participants were recruited and enrolled in the current study. Participants were YAs with high functioning ASD (defined below). They were recruited from local intervention agencies and community ASD support groups in a moderately sized Midwestern city, as well as an in-house waiting list at an Autism Clinic at a private university. As in the past, existing relationships with these 
organizations were utilized and Institutional Review Board (IRB) approval was obtained prior to advertisements and data collection (Schohl et al. 2014). Informed consent was obtained from all individual participants included in the study. A priori power analyses for the omnibus MANOVA were conducted using G*Power 3.1.9.2 (Faul et al. 2009), with a large effect size based on the results of the Gantman et al. (2012) study ( $f=0.54$ for MANOVA). Results indicated that 29 participants would be needed for power to detect differences among groups at the $\beta=0.80$ level. A total of 56 individuals with ASD were enrolled to account for possible attrition, and thus sample size was more than sufficient for adequate power.

Interested families received a telephone-screening interview, administered by a graduate student in a clinical psychology doctoral program, to review inclusion criteria. Because of the scarcity of services available to adults with ASD in the region, participants between the ages of 18 and 28 were invited to participate in the current study. Further, one WL participant was 17 at the time of pretest, but turned 18 by the time of intervention, and was included. Thus, inclusion criteria specified the following: (1) adult participant with ASD being between the ages of 18 and 28; (2) parent report of social difficulties in the adult participant; (3) English fluency for the adult participant with ASD; (4) English fluency and willingness to participate for the parent/caregiver; (5) negative for a history of a major mental illness (such as bipolar disorder, schizophrenia, or psychosis) in the adult participant with ASD; (6) negative for impairments that preclude intervention participation (such as hearing, visual, or physical impairments) in the adult participant with ASD; and (7) adult participant having a previous and current diagnosis of ASD (including High Functioning Autism, Autism Syndrome, or Pervasive Developmental Disorder-NOS). Further, potential adult participants with ASD were screened for the following: (1) meeting ASD criteria on the Autism Diagnostic Observation Schedule-Generic (Lord et al. 2000); (2) having a verbal IQ of 70 or above on the Kaufman Brief Intelligence Test-Second Edition (KBIT-2; Kaufman and Kaufman 2004); and (3) having a desire to learn about how to make friends, via the Mental Status Checklist (Gantman et al. 2012).

Once adult participants with ASD were screened for inclusion criteria, they were randomly assigned to the experimental (EXP) or 
waitlist (WL) group. The only exception to randomization was that a group with one female participant needed to have at least one other female participant, as suggested by the PEERS $\AA$ developers ( $L$. Laugeson personal communication 2010). Due to a much lower rate of females recruited than males, directly related to the proportion of males versus females who are diagnosed with ASD (with a ratio of about 4.5:1; CDC 2016), the researchers would wait until two females could be enrolled and the two were immediately randomized to the next upcoming group as a duo. Both groups participated in pre-test data collection within 1 week of each other, and the EXP group received the PEERS $®$ for Young Adults intervention immediately thereafter. Waitlist participants did not enter the PEERS $₫$ treatment immediately. Post-test data for the EXP group was collected just prior to the final (16th) session of the PEERS $\AA$ intervention. Post-test data was collected approximately 15 weeks after pre-test for the WL group. The WL group received the intervention during the following session, typically during the next academic semester. This design allowed for both groups to be examined over a 16-week period. Table 1 shows the intervention timeline. Each EXP and WL group totaled 24 participants (with no more than 10 participants in each cohort/PEERS $\AA$ provision at a time).

Table 1. Intervention timeline

Time 1

EXP pre-test

WL pre-test
Time 2 (15 weeks)

EXP intervention

No intervention
Time 3

EXP post-test

WL post-test
Time 4

WL intervention

\section{Attrition}

Attrition was expected to be about $20 \%$, which falls within the usual range of randomized controlled trials (Hewitt et al. 2010). Participants who missed three or more sessions or did not have adequate completion of three homework assignments were excused from the intervention and did not complete post-test measures $(n=7)$. Figure 1 shows a CONSORT diagram of participant involvement and completion status. 
NOT THE PUBLISHED VERSION; this is the author's final, peer-reviewed manuscript. The published version may be accessed by following the link in the citation at the bottom of the page.

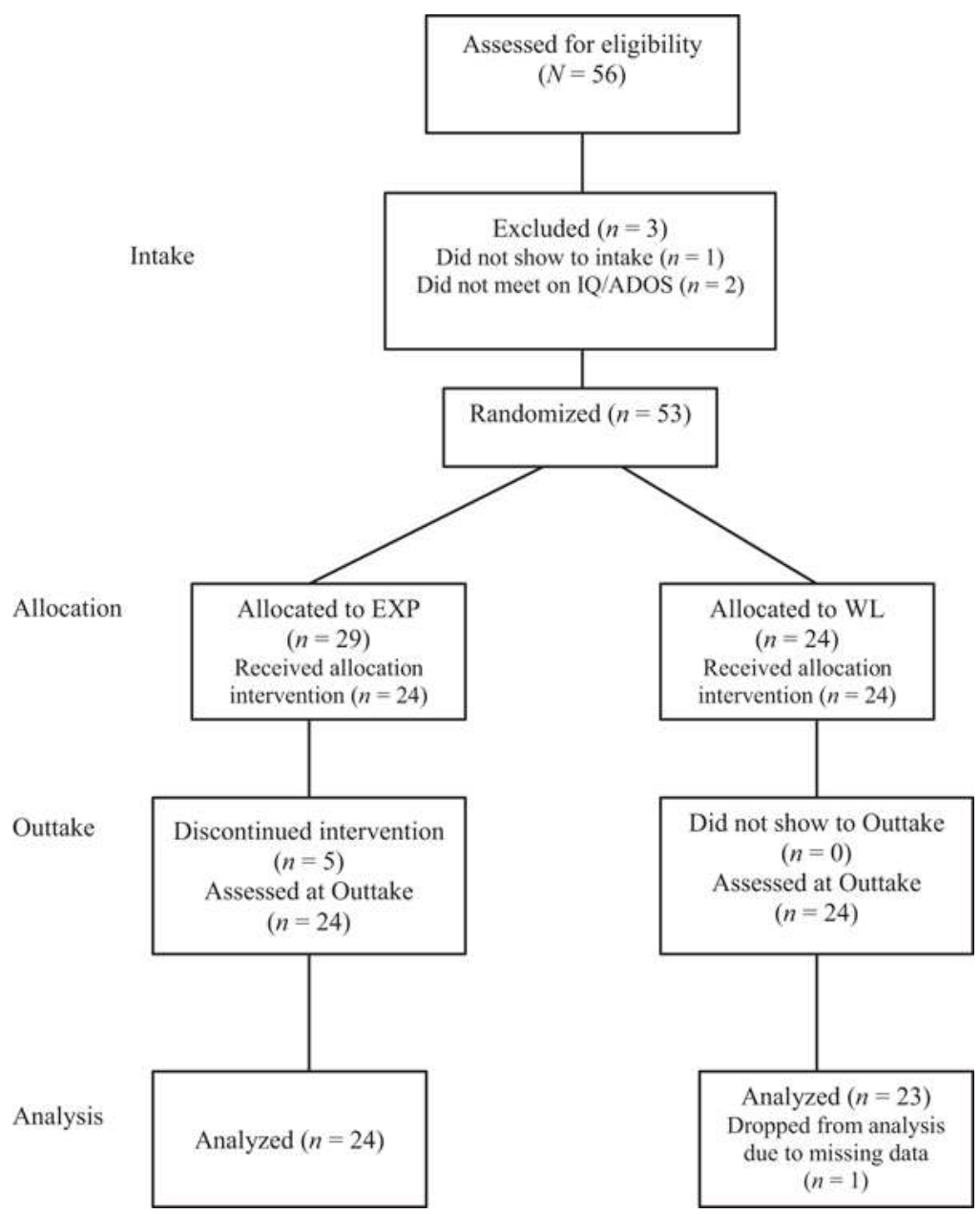

Fig. 1. CONSORT recruitment diagram

\section{Treatment}

PEERS $®$ for Young Adults was delivered in weekly 90-minute simultaneously occurring YA and parent/caregiver group sessions for 16 weeks. The intervention was provided during academic semesters, that is, either fall (September through December) or spring (January through May). The manual, provided by the developers at UCLA, was adhered to for the treatment. The principal investigator received direct instruction via an official PEERS $\AA$ training in Los Angeles, CA and received certification in PEERS $®$ prior to the start of the study. She then trained graduate students in a clinical psychology doctoral program to lead the YA and parent/caregiver groups. The six graduate students who served as group leaders had a minimum of 2 years of clinical, diagnostic, and research practice in ASD. Three of those

Journal of Autism and Developmental Disorders, Vol 46, No. 12 (December 2016): pg. 3739-3754. DOI. This article is (C) Springer and permission has been granted for this version to appear in e-Publications@Marquette. Springer does not grant permission for this article to be further copied/distributed or hosted elsewhere without the express permission from Springer. 
leaders ran YA groups and had obtained at least a Master's degree in Clinical Psychology and had completed coursework in therapy. The leaders received training and supervision directly from the certified leader. The certified leader ran the first YA group, for training purposes. Subsequently, group leaders were trained in the following manner. First, they began by co-leading a parent group with a trained leader or the certified leader. Second, the trainees co-led a YA group with a trained leader or the certified leader. Third, they were allowed to lead a YA group independently. The certified leader conducted weekly supervision with the leaders to ensure quality and accuracy of the intervention and to provide feedback.

Undergraduate research assistants in the lab were trained and overseen directly by the certified leader as behavioral coaches and assistants for the intervention. Coaches' primary responsibilities included enacting behavioral role-plays of appropriate and inappropriate social behavior and assisting with behavioral rehearsals and behavior management. Coaches were also responsible for intervention adherence. That is, coaches followed along with leaders in the protocol, utilizing the manual, and, when necessary, provided fidelity checks [i.e., pointed out a missed item to the leader(s)] to ensure proper adherence to the manualized intervention.

PEERS $®$ for Young Adults sessions began with a homework review from the previous week, and were followed with a didactic lesson. Role-play exercises with the group leader and coaches were utilized to demonstrate appropriate and inappropriate behaviors based on the social skills targeted in a given week. Young adults then practiced the newly learned skills by engaging in behavioral rehearsals with one another, the group leader, and/or coaches.

Concurrent parent/caregiver sessions consisted of a similar, complementary procedure. Weekly homework assignments were reviewed and troubleshooting for challenging issues was discussed. Then, the didactic lesson occurring in the YA session was delivered both in a handout and described verbally by the parent leader. Possible difficulties were discussed and parents/caregivers were provided with information on how to help their YAs complete the assigned homework for the upcoming week. 
NOT THE PUBLISHED VERSION; this is the author's final, peer-reviewed manuscript. The published version may be accessed by following the link in the citation at the bottom of the page.

The YA and parent groups were then reunified. Homework for the upcoming week was assigned and leaders provided one-on-one troubleshooting and feedback regarding missed assignments for the past week and previous plans to complete the current assignment. Homework assignments typically corresponded to the didactic provided in that session and usually involved several components (e.g., make a phone call to another YA group member and join a social group). Group leaders strongly enforced homework compliance and YAs who missed three homework assignments were dismissed from the intervention. Missing more than two sessions also merited dismissal from the treatment.

\section{Measures}

\section{Diagnostic and Screening Measures}

During the baseline pre-test visit, parents/caregivers completed a demographic form and a questionnaire about their YA's health, medication history, and current medication status. Young adults completed the Mental Status Checklist (Gantman et al. 2012), which assesses for YA motivation to make and keep friends. Diagnoses were confirmed using the Autism Diagnostic Observation Schedule-Generic (ADOS-G: Lord et al. 2000), specifically Module 4, which is indicated for use with verbally fluent adolescents and adults. The ADOS represents the gold standard for ASD evaluation and has been shown to have high inter-rater reliability, high inter-item correlations, and high validity (Lord et al. 2002). It is a widely used tool for the diagnostic assessment of ASD in both clinical and research settings. The ADOS-G generates three scores: a Social Interaction Score, a Communication Score, and a Repetitive Behavior Score. The Social Interaction Score and Communication Score are then combined to create the Total Score. For the purposes of this study, the ADOS-G was administered by Clinical Psychology graduate students trained to research-level reliability within the research laboratory. Cut-off scores for inclusion via the ADOS-G consisted of a Total Score of 6 or higher, as these scores are suggestive of ASD, per the manual. Young adults' cognitive functioning was assessed with the Kaufman Brief Intelligence Test-Second Edition (KBIT-2; Kaufman and Kaufman 2004). Cut-off scores for inclusion via the KBIT-2 was a Verbal IQ of 70 or higher. 
NOT THE PUBLISHED VERSION; this is the author's final, peer-reviewed manuscript. The published version may be accessed by following the link in the citation at the bottom of the page.

\section{Experimental Measures: Parent-Report}

Experimental measures were self-administered or read to the individual by a research assistant, based on verbal ability, reading ability, and preference of the individual. All parent-report measures were utilized to examine Aim 1, namely, the replication of the Gantman et al. (2012) study.

Change in social skills was measured using the Social Skills Improvement System-Rating Scales (SSIS-RS; Gresham and Elliott 2008), formerly the Social Skills Rating Scale (SSRS; Gresham and Elliott 1990). This measure was administered to parents of YAs at preand post-test. Although the SSRS was used by the developers of the PEERS $®$ for Young Adults intervention (Gantman et al. 2012), the SSIS-RS was utilized in this study, as it has been shown to be as accurate and is intended for use in intervention research (Gresham et al. 2011). This measure was developed to examine social skills, specifically: communication, cooperation, assertion, responsibility, empathy, engagement, and self-control. This parent-report measure is typically used with children between the ages of 13 and 18, however, because the UCLA PEERS $\AA$ researchers utilized this form beyond this age range (Gantman et al. 2012), the present study did as well, for direct replication purposes. It is a 75 -item rating scale where higher scores indicate greater frequency of a behavior. Although standard scores are typically employed $(M=100 ; S D=15)$, raw scores were utilized to account for the wider age range of the sample; this allowed for the measure to be used outside of the specified age range (without age-based norms). The measure provides a Social Skills total score, a Competing Problem Behavior total score, as well as twelve subscale scores: Communication, Cooperation, Assertion, Responsibility, Empathy, Engagement, Self-Control, Externalizing, Bullying, Hyperactivity/Inattention, Internalizing, and Autism Spectrum. The two total scores were examined. An example of a Social Skills scale item is, "Takes turns in conversations." An example item from the Competing Problem Behavior scale is, "Repeats the same thing over and over" (Gresham et al. 2010). The parent form shows high internal consistency (0.94), high test-retest reliability $(0.84)$, and high validity (0.77) (Gresham et al. 2011). In the current study, internal consistency was acceptable (0.77).

Journal of Autism and Developmental Disorders, Vol 46, No. 12 (December 2016): pg. 3739-3754. DOI. This article is (C) Springer and permission has been granted for this version to appear in e-Publications@Marquette. Springer does not grant permission for this article to be further copied/distributed or hosted elsewhere without the express permission from Springer. 
Change in ASD symptoms was measured using the Social Responsiveness Scale (SRS; Constantino et al. 2003). The measure was administered to the parents of YAs at pre- and post-test. This measure was developed to examine social impairment in ASD, and asks questions such as, "[Your child] is aware of what others are thinking or feeling." It is a 65 -item rating scale that utilizes T-scores $(M=50 ; S D=10)$, where higher scores indicate a greater severity of ASD symptoms. The measure provides a Total score and five subscale scores: Social Awareness, Social Information Processing, Social Communication, Social Avoidance, and Autistic Mannerisms. The Total raw score was used for analyses. This measure shows a high testretest reliability (0.88) and good validity (Constantino et al. 2003). Internal consistency for the present study was good (0.84).

\section{Experimental Measures: Self-Report}

Self-report questionnaires utilized to examine Aim 1 (Replication) included the following: Test of Young Adult Social Skills Knowledge (TYASSK; Gantman et al. 2012), Quality of Socialization Questionnaire for Young Adults (QSQ-YA; Gantman et al. 2012), Empathy Quotient (EQ; Lawrence et al. 2004), and Social and Emotional Loneliness Scale for Adults (SELSA; DiTommaso and Spinner 1993).

PEERS $\&$ knowledge was measured using the TYASSK (Gantman et al. 2012), which was administered to the YAs with ASD at pre- and post-test. This measure was developed to assess knowledge of specific social skills taught during the PEERS ${ }^{\circledR}$ for Young Adults intervention. It was based on the Test of Adolescent Social Skills Knowledge (TASSK; Laugeson et al. 2009) and adapted for YAs of an unspecified age

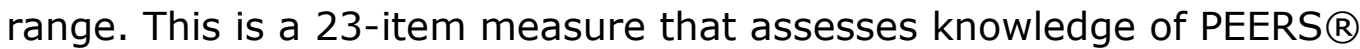
concepts via questions such as, "The most important part of having a conversation is to: (a) trade information or (b) make sure the other person is laughing and smiling" (Gantman et al. 2012). The psychometric properties of the YA version of this measure have not yet been examined. The adolescent version, the TASSK, was found to have low internal consistency (0.56), however the authors attribute this to the large variance in the questions asked and indicate that the items are not expected to "hang together" (Laugeson et al. 2009; Schohl et 
al. 2014). Similarly, in the present study, the internal consistency for this measure was very low (0.22).

Self-report of socialization was measured with the QSQ-YA (Gantman et al. 2012), which was administered to the YAs with ASD at pre- and post-test. This measure was developed to assess frequency of both hosted and invited get-togethers over the prior month, as well as level of Interpersonal Conflict present during those get-togethers. This is a 12-item self-report measure that Gantman et al. (2012) adapted from the Quality of Play Questionnaire (QPQ) for children with ASD (Frankel et al. 2010) for use with adults of an unspecified age range. Young adults were asked two questions: "How many gettogethers did you organize in the last month?" and "How many gettogethers were you invited to last month?" (Gantman et al. 2012). The psychometric properties of the QSQ-YA have not been formally evaluated, and this study did not evaluate them, because the measure consists solely of summing the frequency of the two items. Consistent with prior research (Schohl et al. 2014), number of hosted and invited get-togethers was summed to create a single variable encompassing frequency of all get-togethers.

Self-report of social empathy was measured with the EQ (Lawrence et al. 2004), which was administered to the YAs with ASD at pre- and post-test. This is a 28-item self-report measure of empathy where greater scores indicate more empathic responses. The measure has high internal consistency (0.92) and test-retest reliability (0.97). An example item is, "I am quick to spot when someone in a group is feeling awkward or uncomfortable" (Lawrence et al. 2004). Internal consistency for the present study was found to be marginally acceptable (0.63). It is speculated that young adults with ASD may not be able to report on their experience of empathy to the same degree as their TD peers, and have been shown to score lower on the EQ than age- and gender-matched TD peers (Baron-Cohen and Wheelwright 2004).

Self-report of social and emotional loneliness was measured with the SELSA (DiTommaso and Spinner 1993), which was administered to the YAs with ASD at pre- and post-test. This is a 37item self-report measure that assesses for romantic, social, and family loneliness, where higher scores indicate greater loneliness; the total 
score was examined here. Reponses are on a Likert scale from 1 (disagree strongly) to 7 (agree strongly). The measure has high internal consistency (0.89-0.93) and good validity (DiTommaso and Spinner 1993). An example item is, "I really belong in my family." The SELSA was found to have acceptable internal consistency $(0.71)$ for the present study.

Self-report questionnaires utilized to examine Aim 2 (Extension) included the Liebowitz Social Anxiety Scale-Self-Report (LSAS-SR; Fresco et al. 2001) and the Social Phobia Inventory (SPIN; Connor et al. 2000). Two measures were utilized in order to capture various expressions of social anxiety. Specifically, the LSAS-SR, which was developed to assess for social anxiety disorder, consists mostly of questions regarding anxious symptoms while conducting daily life activities in front of others (i.e., using a public restroom, eating in front of others, etc.), while the SPIN, developed to assess for social phobia, includes items that inquire about physiological symptoms of social anxiety that occur in front of others (i.e., blushing, heart palpitations, trembling, and shaking in front of others). Both measures include items regarding social interaction anxiety and performancebased anxiety. Because these measures were developed while the DSM-IV-TR was in use, the creators used the terminology "social anxiety disorder" and "social phobia," respectively.

Self-report of social anxiety was measured with the LSAS-SR (Fresco et al. 2001), which was administered to the YAs with ASD at pre- and post-test. This is a 24-item self-report measure that shows high internal consistency (0.96) and high convergent validity with other measures of the same construct (0.49-0.73) (Fresco et al. 2001). The questionnaire asks to what degree different situations evoke both fear and avoidance from the respondent over the past week, using a Likert scale from 0 (none) to 3 (severe). Higher scores indicate greater severity of impairment. An example item is, "[How anxious or fearful do you feel when/how often do you avoid] meeting strangers?" (Fresco et al. 2001). The LSAS-SR showed excellent internal consistency in the present study (0.97), similar to the developers' findings. Our sample demonstrated high levels of social anxiety at pre-test. Specifically, 30 out of 47 participants showed at least moderate social anxiety, with 6 in the moderate range, 11 in the marked range, 8 in the severe range, and 5 in the very severe range. 
Self-report of social phobia was measured with the SPIN (Connor et al. 2000), which was administered to the YAs with ASD at pre- and post-test. This measure was developed to assess presence of social phobia, where higher scores indicate higher levels of social phobia. It is a 17-item self-report measure that shows high test-retest reliability (0.78), high internal consistency (0.82-0.94), and adequate convergent validity (0.57) (Connor et al. 2000). The questionnaire asks individuals about their symptoms over the past week, and thus, is used to capture current levels social phobia. An example question is, "I avoid activities in which I am the center of attention" (Connor et al. 2000). The SPIN has been utilized in clinical research with both adolescent (Ranta et al. 2007) and adult populations (Antony et al. 2006). Internal consistency for this measure was found to be consistent with the developers' report, and fell in the excellent range (0.94). The present sample also showed high levels of social phobia at pre-test with 11 in the mild range, 8 in the moderate range, 6 in the severe range, and 7 in the very severe range.

The means at pre-test for each of the above Replication scales/subscales in this study were generally comparable to the means at pre-test in the Gantman et al. (2012) study.

\section{Results}

\section{Data Screening}

All statistical analyses were conducted using SPSS 22.0 (IBM Corp. 2013). An alpha level of 0.05 was used as the significance criterion for hypothesis tests. Data were screened for normality, impossible values, and outliers. Three outliers $(0.02 \%$ percent of the total data) were identified, two in the QSQ-YA pre-test data (both a value of 15) and one in the EQ post-test data (value of 66); these three scores were subsequently Winsorized to the next highest value (11 for the QSQ-YA, 54 for the EQ; Tabachnick and Fidell 2013). The screening protocol was subsequently re-run and data were found to be within normal limits. Skew and kurtosis were within normal limits. Missing data were found to be missing completely at random. One participant was missing the entirety of his post-test data and was excluded from analysis (Tabachnick and Fidell 2013). Multiple 
imputation (five iterations) was then conducted for any remaining missing items from the outcome measures (Tabachnick and Fidell 2013). The imputed data points did not exceed the recommendation of no more than $10 \%$ of the data (Tabachnick and Fidell 2013); specifically, they constituted $2 \%$ of the total data (there were 21 imputed data points out of a total 1034 across scales/subscales). One participant was missing data on socioeconomic status, as measured by total household income. This value was estimated with the mean for the remainder of the sample $(M=4 ; 75-100 \mathrm{~K})$.

\section{Examination of Group and Cohort Differences}

T-tests and Chi square tests for independence were employed to assess for EXP versus WL group differences on demographic variables. As predicted, no significant differences were uncovered for $Y A$ gender $\left(X^{2}=1.08, p=.298\right.$, Cramer's $\left.V=0.152\right)$, socioeconomic status $\left(X^{2}=9.261, p=.055\right.$, Cramer's $\left.V=0.444\right)$, primary parent/caregiver education $\left(X^{2}=9.344, p=.096\right.$, Cramer's $\left.V=0.446\right)$, YA race $\left(X^{2}=3.253, p=.354\right.$, Cramer's $\left.V=0.266\right)$, YA ethnicity $\left(X^{2}=2.002\right.$, $p=.157$, Cramer's V $=0.211)$, KBIT-2 Verbal IQ $[t(45)=0.412$, $p=.682$, two tailed, $95 \% \mathrm{CI}(-10.766,16.298)]$, ADOS-G total score $[t(44)=0.486, p=.629$, two tailed, $95 \% \mathrm{CI}(-1.466,2.398)]$ or YA age $[t(34.690)=1.828, p=.076$, two-tailed, $95 \%$ CI $(-0.155$, 2.944)]. Table 2 presents the mean demographic variables for both groups. Furthermore, participants who chose to withdraw or were excused from the intervention did not differ from the participants in the EXP group who completed the study, based on YA age $[t(28)=0.161, p=.873$, two tailed, $95 \%$ CI $(-2.926,3.426)]$, YA race $\left(\mathrm{X}^{2}=1.875, p=.599\right.$, Cramer's $\left.\mathrm{V}=0.250\right)$, socioeconomic status $\left(X^{2}=3.333, p=.649\right.$, Cramer's $\left.V=0.333\right)$, ADOS-G Total Score $[t(28)=-0.930, p=.361$, two tailed, $95 \% \mathrm{CI}(-4.138,1.554)]$, KBIT-2 Verbal IQ $[t(29)=0.590, p=.560$, two tailed, $95 \%$ CI $(-13.614,24.650)]$, or measures of social anxiety [LSAS-SR, $t(26)=-0.319, p=.752$, two tailed, $95 \%$ CI $(-44.381,32.464)$; or SPIN, $t(27)=-0.130, p=.897$, two tailed, $95 \%$ CI $(-19.241$, 16.941)] at pre-test. Potential differences between cohorts for the experimental group were examined and no differences in a robust outcome measure were uncovered $(F(4,23)=0.308, p=.869)$. 
Table 2. Means and standard deviations for experimental and waitlist control groups at pre-test

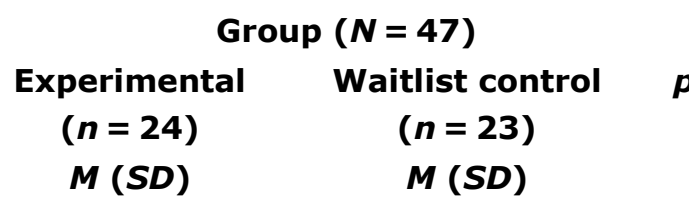

\begin{tabular}{|c|c|c|c|}
\hline Age (years) & $20.92(3.31)$ & $19.52(1.70)$ & $\mathrm{ns}$ \\
\hline Sex ( $\%$ female $)$ & 25.0 & 13.0 & ns \\
\hline Race (\% Caucasian) & 83.3 & 90.9 & ns \\
\hline Ethnicity (\% non-Hispanic) & 100 & 91.3 & ns \\
\hline \multicolumn{3}{|l|}{ Household income (\%) } & ns \\
\hline Under $25 \mathrm{~K}$ & 4.2 & 8.7 & \\
\hline $25-50 \mathrm{~K}$ & 4.2 & 26.1 & \\
\hline $50-75 \mathrm{~K}$ & 29.2 & 4.3 & \\
\hline $75-100 \mathrm{~K}$ & 16.7 & 26.1 & \\
\hline Over $100 \mathrm{~K}$ & 45.8 & 34.8 & \\
\hline \multicolumn{3}{|l|}{ Primary parent education (\%) } & ns \\
\hline High school completion & 0.0 & 21.7 & \\
\hline Vocational/technical training & 12.5 & 4.3 & \\
\hline Some college & 12.5 & 21.7 & \\
\hline Bachelor's degree & 54.2 & 39.1 & \\
\hline Master's degree & 16.7 & 4.3 & \\
\hline Doctoral degree & 4.2 & 8.7 & \\
\hline KBIT-2 verbal IQ & $93.38(22.95)$ & $90.61(23.10)$ & ns \\
\hline ADOS-G total score & $11.88(2.83)$ & $11.41(3.65)$ & ns \\
\hline \multicolumn{4}{|c|}{$\begin{array}{l}\text { The following variables had different } n \text { values: Waitlist race }(n=22) \text {, Waitlist ADOS-G } \\
\text { total score }(n=22) \text {, experimental ethnicity }(n=22) \text {, and experimental household } \\
\text { income }(n=23) \\
\text { KBIT-2 Kaufman Brief Intelligence Test-Second Edition, ADOS-G autism diagnostic } \\
\text { observation schedule-generic, } p \text { probability, } n \text { s not significant }\end{array}$} \\
\hline
\end{tabular}

\section{Omnibus MANOVA}

In order to evaluate the large number of outcome measures, all dependent variables were entered into an omnibus Group (EXP versus WL) by Time (pre- versus post-intervention) repeated measures, multivariate analysis of variance (MANOVA). Results indicated a significant main effect of Group for the combined outcome variables (Wilks' Lambda $=0.475 ; F(11,35)=3.523, p=.002$ ), a significant main effect of Time (Wilks' Lambda $=0.304 ; F(11,35)=7.291$, $p=.001$ ), both of which were further qualified by a significant multivariate Group by Time interaction (Wilks' Lambda $=0.279 ; F(11$, $35)=8.236, p=.001$ ). Table 3 shows the means, standard deviations, 
and $p$-values for the omnibus Group by Time interaction for the experimental measures. An intent-to-treat analysis (Wright and Sim 2003) utilizing last observation carried forward imputation was subsequently run and no differences were uncovered at the multivariate or univariate level.

Table 3. Means and standard deviations for group by time interaction of the outcome measures for experimental and waitlist control groups at pre- and post-test

\begin{tabular}{|c|c|c|c|c|c|}
\hline & \multicolumn{4}{|c|}{ Group $(N=47)$} & \multirow[t]{4}{*}{$\boldsymbol{p}$} \\
\hline & \multicolumn{2}{|c|}{ Experimental $(n=24)$} & \multicolumn{2}{|c|}{ Waitlist control $(n=23)$} & \\
\hline & Pre & Post & Pre & Post & \\
\hline & $M(S D)$ & M & $M(S D)$ & $M(S D)$ & \\
\hline \multicolumn{6}{|l|}{ Young adult } \\
\hline TYASSK & $17.42(2.62)$ & $24.13(3.01)$ & $17.55(3.53)$ & $17.22(3.69)$ & 0.001 \\
\hline QSQ-YA & $2.04(2.99)$ & $3.25(2.66)$ & $1.94(3.33)$ & $1.52(2.81)$ & 0.047 \\
\hline $\mathrm{EQ}$ & $29.88(9.39)$ & $33.54(11.81)$ & $28.65(7.59)$ & $26.71(7.92)$ & 0.013 \\
\hline SELSA-ER & $58.33(13.30)$ & $57.08(12.12)$ & $55.75(14.10)$ & $57.07(14.16)$ & 0.373 \\
\hline SELSA-FL & $22.21(8.38)$ & $23.50(10.27)$ & $26.86(16.51)$ & $27.08(15.69)$ & 0.599 \\
\hline SELSA-SL & $45.38(22.96)$ & $45.13(21.11)$ & $56.19(15.98)$ & $50.42(15.48)$ & 0.158 \\
\hline LSAS-SR & $56.79(32.56)$ & 50.96 (31.99) & $68.60(24.48)$ & $65.58(24.60)$ & 0.457 \\
\hline SPIN & $27.25(16.69)$ & $25.25(16.48)$ & $31.87(14.45)$ & $31.38(14.09)$ & 0.586 \\
\hline \multicolumn{6}{|l|}{ Parent } \\
\hline SSIS-RS SS & $114.29(15.01)$ & $123.92(20.72)$ & $110.04(15.79)$ & $114.72(13.24)$ & 0.219 \\
\hline SSIS-RS CPB & 63.67 & $57.92(12.65)$ & $69.70(8.93)$ & $73.46(10.28)$ & 0.001 \\
\hline SRS & $96.04(26.01)$ & $82.08(32.10)$ & $105.57(23.68)$ & $107.04(21.76)$ & 0.00 \\
\hline
\end{tabular}

TYASSK test of young adult social skills knowledge, $Q S Q-Y A$ quality of socialization questionnaire, young adult, $E Q$ empathy quotient, SELSA-ER social and emotional Ioneliness scale for adults, emotion/romantic, SELSA-FL social and emotional Ioneliness scale for adults, family loneliness, SELSA-SL social and emotional loneliness scale for adults, social loneliness, $L S A S-S R$ Liebowitz social anxiety scale-self-report; SPIN social phobia inventory, SSIS-RS SS social skills improvement system, revised scales, social skills, SSIS-RS CPB social skills improvement system, revised scales, competing problem behaviors, SRS social responsiveness scale, $p=$ probability, univariate group by time INTERACTION $p$ value from MANOVA ${ }^{a} Q S Q-Y A$ range at pre-test for both EXP and WL: 0-11

\section{Aim 1: Univariate ANOVAs and Simple Effects for the Replication}

Further evaluation of the replication outcome measures at the univariate level, using Group (EXP versus WL) by Time (pre- versus post-intervention) repeated measures analyses of variance (ANOVAs), revealed that four Aim 1 (Replication) measures reached significance. 
Post hoc simple effects tests at the univariate level were subsequently conducted using one-way repeated measures ANOVAs separately by group; $F$ values were corrected using the mean square error and degrees of freedom from the omnibus test. Utilizing this method preserved power and statistically corrected for the number of analyses conducted, thus reducing, though not eliminating, our risk of Type I error.

\section{Hypothesis 1: Social Skills and Social Responsiveness}

The first hypothesis was partially supported. It was hypothesized that parents of the YAs in the EXP ASD group would report significantly improved YA social skills and social responsiveness on the SSIS-RS and SRS over the WL group. Improvement in Social Skills (SSIS-RS SS) was not significant at the multivariate level, though the simple effects test was significant at the univariate level, showing that the EXP group demonstrated significant improvement in Social Skills over time $\left(F(1,45)=12.030, p=.006\right.$, partial $\left.\eta^{2}=0.287\right)$, while the $W L$ group did not $(F(1,45)=2.726, p=.059$, partial $\left.\eta^{2}=0.153\right)$. A significant Group by Time interaction at the univariate level for the SSIS-RS Competing Problem Behavior scale was found, $F(1,45)=16.051, p=.001$, partial $\eta^{2}=0.263$. Simple effects tests indicated that the EXP group significantly decreased in Competing Problem Behavior (SSIS-RS CPB) $(F(1,45)=11.989, p=.005$, partial $\left.\eta^{2}=0.293\right)$, while the WL group significantly increased over time $(F(1$, $45)=4.915, p=.016$, partial $\left.\eta^{2}=0.235\right)$. Further, a significant Group by Time interaction at the univariate level on the SRS was found, $F(1$, $45)=7.419, p=.009$, partial $\eta^{2}=0.142$. Simple effects tests indicated that the EXP group demonstrated significant improvement in social responsiveness (SRS) $\left(F(1,45)=12.401, p=.004\right.$, partial $\left.\eta^{2}=0.304\right)$ while the WL group did not $(F(1,45)=0.132, p=.608$, partial $\left.\eta^{2}=0.008\right)$.

\section{Hypothesis 2: Social Skills Knowledge}

The second hypothesis was supported. It was hypothesized that the YAs in the EXP ASD group would demonstrate significant

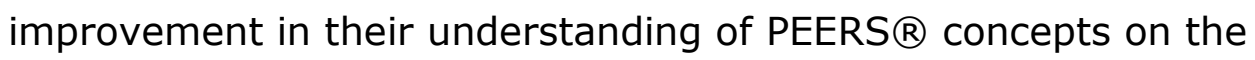
TYASSK over the WL group. A significant Group by Time interaction at the univariate level for the TYASSK was found, $F(1,45)=85.602$, 
$p=.001$, partial $\eta^{2}=0.655$. Simple effects tests indicated that the EXP group demonstrated significant improvement in social skills knowledge (TYASSK) $\left(F(1,45)=159.017, p=.001\right.$, partial $\left.\eta^{2}=0.843\right)$ while the WL group did not $\left(F(1,45)=0.363, p=.479\right.$, partial $\left.\eta^{2}=0.023\right)$.

\section{Hypothesis 3: Empathy}

The third hypothesis was supported. It was hypothesized that the YAs in the EXP ASD group would show significant improvement in their self-report of empathy on the EQ over the WL group. A significant Group by Time interaction at the univariate level for the EQ was found, $F(1,45)=6.740, p=.013$, partial $\eta^{2}=0.130$. Simple effects tests indicated that the EXP group demonstrated significant improvement in empathy (EQ) $\left(F(1,45)=5.887, p=.044\right.$, partial $\left.\eta^{2}=0.165\right)$ while the WL group did not $\left(F(1,45)=1.582, p=.144\right.$, partial $\left.\eta^{2}=0.094\right)$.

\section{Hypothesis 4: Loneliness}

The fourth hypothesis was not supported. It was hypothesized that the YAs in the EXP ASD group would demonstrate significantly lower self-report of social and emotional loneliness over time on the SELSA than the WL group. The SELSA showed no significant change for the EXP group on any of the three subscales.

\section{Hypothesis 5: Direct Social Interaction}

The fifth hypothesis was supported. It was hypothesized that the YAs in the EXP ASD group would report a significantly greater number of direct social interactions with peers over time on the QSQYA than WL. A significant Group by Time interaction at the univariate level for the QSQ-YA was found $F(1,45)=4.164, p=.047$, partial $\eta^{2}=0.085$. Simple effects tests indicated that the EXP group demonstrated a marginally significant improvement in quality of socialization (QSQ-YA) $\left(F(1,45)=4.712, p=.059\right.$, partial $\left.\eta^{2}=0.147\right)$ while the WL group did not $(F(1,45)=0.533, p=.423$, partial $\left.\eta^{2}=0.029\right)$. 


\section{Aim 2: Univariate ANOVAs and Simple Effects for the Extension}

\section{Hypothesis 6: Social Anxiety}

The sixth hypothesis was partially supported. It was hypothesized that the YAs in the EXP ASD group would report lower levels of social anxiety on the LSAS-SR and lower levels of social phobia on the SPIN over time than the WL group. Both Aim 2 (Extension) measures, the LSAS-SR and the SPIN, failed to reach significance upon follow-up from the MANOVA at the Group by Time univariate level. However, observed power for these measures was found to be very low ( 0.114 and 0.084 , respectively). A posteriori power analyses were conducted with obtained power; results indicated a small effect size for both measures and over 800 participants would be needed for adequate power. Exploratory analyses were conducted to investigate whether effects might be more robust using pairedsamples $t$ tests separately by group, versus the more demanding multivariate model. Results from these univariate analyses revealed that the EXP group demonstrated significant improvement in social anxiety (LSAS-SR) over time $(t(23)=2.535, p=.019)$ while the WL group did not $(t(22)=1.009, p=.324)$. Social phobia (SPIN) decreased in the EXP group over time, while the WL group showed no change; however, these differences were not statistically significant in the exploratory analyses. Considering clinical changes in these measures, fewer EXP YAs at post-test fell into clinical ranges for social anxiety (LSAS-SR) with 12 in the clinically significant range at pre- and 9 at post-intervention, the WL group had 14 in the clinically significant range at pre- and 15 at post-test. For social phobia (SPIN), 15 were in the clinically significant range at pre- and 15 at post-intervention, though scores were generally lower; WL had 17 at pre- and 17 at post-test. Young adults in the EXP group showed a decline in severity of social anxiety symptoms. On the LSAS-SR, 2 EXPs fell in the moderate range at pre-, with 3 at post-test; 4 in the marked range at pre-, with 2 at post-test; 3 in the severe range at pre-, with 2 at posttest; and 3 in the very severe range at pre- with 2 at post-test. For the SPIN, 5 EXPs fell in the mild range at pre-, with 7 at post-test; 3 in the moderate range at pre-, with 4 at post-test; 3 in the severe range 
at pre-, with 1 at post-test; and 4 in the very severe range at prewith 3 at post-test.

\section{Discussion}

The present study examined the impact of a friendshipdevelopment based social skills intervention for YAs with ASD. Although existing research has demonstrated the efficacy of this intervention (Gantman et al. 2012), and the developers have recently replicated their findings (Laugeson et al. 2015), this is, to our knowledge, the first independent replication. Results demonstrate further support for the efficacy of the PEERS® for Young Adults intervention, in that five out of eleven outcome measures showed significant improvement for the YAs in the experimental group.

The majority of the Aim 1, Replication, hypotheses were supported and align with the results from the original study (Gantman et al. 2012). First, parents of the YAs in the experimental ASD group reported improvement in YA social skills, specifically fewer problem behaviors and better social responsiveness. Second, YAs in the experimental ASD group demonstrated significant improvement in

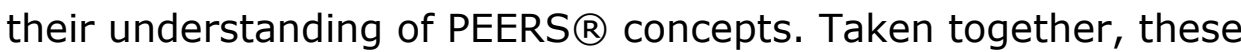
findings suggest not only a strong retention of the skills taught, but also imply that these skills are important and relevant to YAs with ASD. Isolating and targeting social skills knowledge has been found to be an important component of successful treatment of YAs with ASD. Because many individuals with ASD show a marked rigidity and limited understanding of the nuances of social interaction (Anckarsäter et al. 2006; Bowler et al. 2008), the manner in which social skills are concretized in PEERS $\cap$ is likely a strong predictor of success in gaining and utilizing social skills knowledge. Third, YAs in the experimental ASD group showed significant improvement in self-report of empathy. Because mechanisms of empathy were not directly investigated for the purpose of the present study, only speculation is possible. However, findings suggest that, through the development of social skills, YAs may have been able to gain further insight into the experiences of others. Empathy, specifically perspective taking, is a strong predictor of relationship satisfaction (Davis and Oathout 1987), is considered a prosocial behavior, and as such is an important factor for obtaining 
and maintaining a job, as well as job satisfaction (McNeely and Meglino 1994). Further, the development of empathy in adolescence has been found to predict overall social competence in young adulthood (Mathias and Steiger 2014), so targeting these behaviors as soon as possible in young adulthood may have important implications for later adulthood, as well. Fourth, the YAs in the experimental ASD group reported a significantly greater number of direct social interactions with peers over time. Direct contact with peers is very important for YAs to hone their newly developing social skills (Gantman et al. 2012). Although not all YAs in our sample exhibited high levels of social anxiety at pre-test, many did. Again, because the mechanisms of social anxiety were not explored here, it is unknown which processes may be at play. However, results that direct social interaction increased may suggest that these YAs developed and implemented the necessary social skills to engage with peers, which may impact social anxiety symptoms, as discussed below.

In contrast to the original study, the current study did not uncover a significant change in self-report of social and emotional loneliness over time among the YAs in the experimental group. This was thought to be due to potential cohort differences amongst this sample compared with that of the Gantman et al. (2012) study. Potential differences were therefore examined and the findings are described here. First, the present sample did not have comparable levels of social and emotional loneliness at pre-test as in the original study (Gantman et al. 2012) SELSA total means/SDs at pre-test: EXP, 132.6 (33.7); WL, 133.2 (30.2); Present study at pre-test: EXP, 125.92 (34.46); WL, 138.80 (39.33) specifically, the experimental group in this study exhibited lower levels of loneliness than that of the Gantman et al. (2012) group. This may have limited the improvement that participants in that group were able to make. Second, the present sample was found to show a smaller decline in loneliness than the original sample (Gantman et al. 2012) SELSA difference scores from pre- to post-test: EXP, -12.67 ; WL, 4.50; Present study: EXP, -0.21 ; $W L,-4.23$. Finally, the present sample may not have been as competent at reporting their experiences of loneliness as the original sample; however, this study was unable to directly examine this hypothesis. 
NOT THE PUBLISHED VERSION; this is the author's final, peer-reviewed manuscript. The published version may be accessed by following the link in the citation at the bottom of the page.

Aim 2 proposed to extend the original Gantman et al. (2012) study by examining changes in social anxiety and social phobia in the YAs with ASD in PEERS $\otimes$. In exploratory analyses, results indicated a significant decrease in self-report of social anxiety from pre- to postintervention among the YAs with ASD in the experimental group. Although the results for social phobia did not reach traditional levels of significance, the current study uncovered a decrease in self-report of these symptoms over time in the experimental group, that is, changes in the expected direction. These results suggest that the PEERS $\otimes$ for Young Adults intervention may help to improve symptoms of social anxiety and social phobia. Although the present study did not specifically examine the mechanisms of this response to the intervention, several factors may be at play. Specifically, the development of social skills may break the cycle of fear and avoidance of social interaction, as posited by Bellini (2006), the in-session exposure to and direct interaction with same-aged peers, via behavioral rehearsals, as well as weekly homework assignments wherein YAs practiced newly learned social skills with peers outside of session may also contribute to a decrease in social anxiety symptoms at post-intervention. It should be noted that these findings are limited and should be interpreted with caution as further exploration and replication of the current results are merited. Although the number of participants in each category on self-report measures of social anxiety generally decreased from pre- to post-intervention, it is unknown whether individuals with high levels of social anxiety would be best

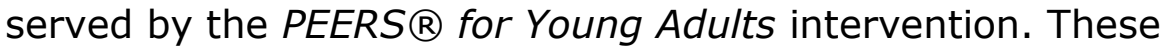
preliminary findings, nonetheless, have important implications for social anxiety symptoms among YAs with ASD who receive the intervention.

This is the first known independent replication of the UCLA PEERS $®$ for Young Adults studies (Gantman et al. 2012; Laugeson et al. 2015), and, thus, provides evidence to the successful translation of the PEERS® for Young Adults content outside of the site of development, and potential accessibility of this efficacious intervention. Few resources are needed to conduct the intervention, showing exceptional promise for general use. 
NOT THE PUBLISHED VERSION; this is the author's final, peer-reviewed manuscript. The published version may be accessed by following the link in the citation at the bottom of the page.

\section{Limitations and Future Directions}

One major limitation of the present study was the lack of diversity within the sample. The sample was comprised of primarily male YAs who were Caucasian. In order to generalize these findings more broadly, future studies should enroll a more diverse participant sample. A second limitation was the lack of third-party observation of changes in behavior for the YAs. Because both reporters, YAs and their parents, are involved in treatment, non-specific treatment effects, such as mere involvement in a group or receiving attention for their difficulties, may have impacted their report. Further, although internal consistency for the measures used was generally high, use of third party observation would improve the validity of findings over self- and parent-report alone. This is particularly important for constructs that may be more challenging for YAs with ASD to report upon (i.e., selfreport measures with lower internal consistency for this population), such as empathy. Future studies could employ the use of a third party reporter such as a teacher or other relative of the YA, or a blinded third party observer to facilitate coding of YA behavior from pre- to post-intervention. This could provide further insight into the behavioral changes related both to social skills and anxiety. Another mechanism of more objective report of change could be with electrophysiological instruments such as galvanic skin response, heart rate, or electroencephalogram. These measures may be more reliable than self- or parent-report. A third limitation was the use of self-report questionnaires to examine social anxiety. Although anxiety, as an internalizing disorder, may be difficult for parents/caregivers to accurately assess, especially as children get older (Achenbach et al. 1987), assessing the various manifestations of anxiety, including social anxiety, via parent report may be useful. Research suggests that individuals with ASD may lack the necessary insight to report their symptoms of anxiety (Baron-Cohen et al. 1985; Capps et al. 1992; Gillott et al. 2001), furthering the importance of gaining parent report of symptoms. Obtaining report from both parent and YA would be pertinent, as parent- and self-report of internalizing symptoms may not always demonstrate ideal agreement (Achenbach et al. 1987; Stanger and Lewis 1993). Utilizing an interview format would also likely improve the sensitivity and specificity of changes in anxiety symptoms over the course of the intervention. Furthermore, anxiety 
among individuals with ASD may differ from TD individuals (Hadwin et al. 1998; Kerns and Kendall 2012). Thus, future studies should employ a more rigorous evaluation of anxiety symptoms, perhaps by conducting a parent-report interview, in particular the Anxiety Disorders Interview Schedule, Adult (ADIS; Brown et al. 1994) in conjunction with the ADIS Addendum for ASD that is currently in development (Kerns et al. 2014). A fourth limitation was the lack of a longer-term follow-up. Future studies should utilize a 6- or 12-month follow up to elicit further evaluation of the long-term efficacy of the

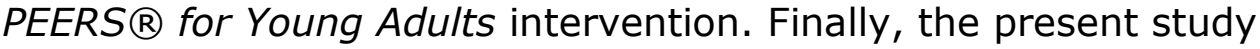
employed many post hoc analyses (16) to fully examine the results of the omnibus MANOVA. Although corrections to the $F$ values were made, this large number of analyses may have increased our risk of Type I error.

The PEERS $®$ for Young Adults intervention was not developed to address all social skills necessary for independent functioning. Possible future directions for this, and other interventions, may include a focus on the development of other skills for life circumstances that inherently rely on social interactions. Such skills may include: job obtainment and maintenance skills, as well as general adaptive functioning skills, the latter of which have been demonstrated to be especially important for long-term positive outcomes (Farley et al. 2009).

In sum, the findings of the present study provide further support for the efficacy of the PEERS $®$ for Young Adults intervention at improving social skills behavior, social responsiveness, social skills knowledge, empathy, and social anxiety among YAs with ASD. The

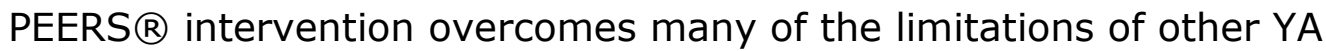
social skills interventions, in that it utilizes well-established techniques for efficaciously teaching social skills to individuals with ASD (Gantman et al. 2012). In conclusion, the findings of this study demonstrate strong support for the PEERS® for Young Adults social skills intervention as a viable tool for improving challenges common to YAs with ASD. 
NOT THE PUBLISHED VERSION; this is the author's final, peer-reviewed manuscript. The published version may be accessed by following the link in the citation at the bottom of the page.

\section{Acknowledgments}

The authors would like to acknowledge grant support from the Autism Society of Southeastern Wisconsin (ASSEW) and Marquette University. The authors would like to thank the families for their participation in our research, as well as acknowledge the Marquette Autism Project undergraduate research team for their diligent work on this project. This paper was presented at the International Meeting for Autism Research (IMFAR) May 2016 conference

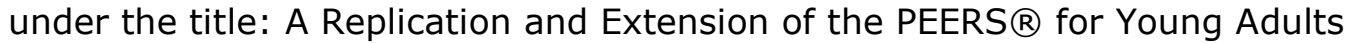
Social Skills Intervention. This paper was originally prepared as the master's thesis for the lead author: Alana J. McVey, under the same title. The lead author would like to acknowledge Nicholas Heck, Ph.D. and Michael Wierzbicki, Ph.D. for their supervision of this work as thesis committee members. Finally, the authors wish to extend their gratitude to Dr. Elizabeth Laugeson, Psy.D., UCLA for her assistance in offering the PEERS $\mathbb{R}$ interventions in Wisconsin.

\section{Author Contributions}

AM conceived of the study, participated in its design and coordination, facilitated delivery of the intervention, conducted the statistical analyses and interpretation of the data, and drafted the manuscript; $\mathrm{BD}, \mathrm{KW}, \mathrm{SP}$, and JK participated in the delivery of the intervention and data acquisition; CLC, CC, and EV participated in the delivery of the intervention; NG participated in the conception and design of the study; AVVH assisted in the conception, design, and coordination of the study, assisted with the statistical analysis and interpretation of the data, and revised the manuscript. All authors read and approved the final manuscript.

\section{Compliance with Ethical Standards}

\section{Research Involving Human and Animal Rights}

All procedures performed in studies involving human participants were in accordance with the ethical standards of the institutional and/or national research committee and with the 1964 Helsinki declaration and its later amendments or comparable ethical standards. This article does not contain any studies with animals performed by any of the authors. 
NOT THE PUBLISHED VERSION; this is the author's final, peer-reviewed manuscript. The published version may be accessed by following the link in the citation at the bottom of the page.

\section{References}

Achenbach, T. M., McConaughy, S. H., \& Howell, C. T. (1987).

Child/adolescent behavioral and emotional problems: Implications of cross-informant correlations for situational specificity. Psychological Bulletin, 101(2), 213-232. doi:10.1037/0033-2909.101.2.213.

American Psychiatric Association. (2000). Diagnostic and statistical manual of mental disorders (4th ed., text rev.). American Psychiatric Association: Washington, DC.

American Psychiatric Association. (2013). Diagnostic and statistical manual of mental disorders (5th ed). American Psychiatric Association: Washington, DC.

Anckarsäter, H., Stahlberg, O., Larson, T., Hakansson, C., Jutblad, S. B., Niklasson, L., ... Cloninger, C. R., et al. (2006). The impact of ADHD and autism spectrum disorders on temperament, character, and personality development. The American Journal of Psychiatry, 163(7), 1239-1244. doi:10.1176/foc.8.2.foc269.

Antony, M. M., Coons, M. J., McCabe, R. E., Ashbaugh, A., \& Swinson, R. P. (2006). Psychometric properties of the social phobia inventory: Further evaluation. Behaviour Research and Therapy, 44(8), 11771185. doi: $10.1016 /$ j.brat.2005.08.013.

Barnhill, G. P. (2007). Outcomes in adults with Asperger syndrome. Focus on Autism and Other Developmental Disabilities, 22(2), 116-126. doi:10.1177/10883576070220020301

Baron-Cohen, S., Leslie, A. M., \& Frith, U. (1985). Does the autistic child have a "theory of mind"? Cognition, 21(1), 37-46. doi:10.1016/00100277(85)90022-8.

Baron-Cohen, S., \& Wheelwright, S. (2003). The Friendship Questionnaire: An investigation of adults with Asperger syndrome or high-functioning autism, and normal sex differences. Journal of Autism and Developmental Disorders, 33(5), 509-517. doi: $10.1023 / A: 1025879411971$.

Baron-Cohen, S., \& Wheelwright, S. (2004). The empathy quotient: an investigation of adults with Asperger syndrome or high functioning autism, and normal sex differences. Journal of Autism and Developmental Disorders, 34(2), 163-175. doi:10.1023/B:JADD.0000022607.19833.00.

Baron-Cohen, S., Wheelwright, S., Skinner, R., Martin, J., \& Clubley, E. (2001). The autism-spectrum quotient (AQ): Evidence from asperger syndrome/high-functioning autism, malesand females, scientists and mathematicians. Journal of Autism and Developmental Disorders, 31(1), 5-17. doi:10.1023/A:1005653411471.

Journal of Autism and Developmental Disorders, Vol 46, No. 12 (December 2016): pg. 3739-3754. DOI. This article is (C) Springer and permission has been granted for this version to appear in e-Publications@Marquette. Springer does not grant permission for this article to be further copied/distributed or hosted elsewhere without the express permission from Springer. 
Barry, C. M., Madsen, S. D., Nelson, L. J., Carroll, J. S., \& Badger, S. (2009). Friendship and romantic relationship qualities in emerging adulthood: Differential associations with identity development and achieved adulthood criteria. Journal of Adult Development, 16(4), 209-222. doi:10.1007/s10804-009-9067-x.

Bauminger, N., Shulman, C., \& Agam, G. (2003). Peer interaction and Ioneliness in high-functioning children with autism. Journal of Autism and Developmental Disorders, 33(5), 489-507. doi: $10.1023 / A: 1025827427901$.

Bellini, S. (2006). The development of social anxiety in adolescents with autism spectrum disorders. Focus on Autism and Other Developmental Disabilities, 21(3), 138-145. doi:10.1177/10883576060210030201.

Bowler, D. M., Gaigg, S. B., \& Gardiner, J. M. (2008). Subjective organisation in the free recall learning of adults with Asperger's syndrome. Journal of Autism and Developmental Disorders, 38(1), 104-113. doi: 10.1007/s10803-007-0366-4.

Brown, T. A., Barlow, D. H., \& Di Nardo, P. A. (1994). Anxiety disorders interview schedule adult version: Client interview schedule. Oxford University Press. Retrieved from https://books.google.com/books?hl=en\&lr=\&id=xpR6V3rboxwC\&oi=fn $\mathrm{d} \& p g=P P 2 \& \mathrm{dq}=$ anxiety+interview+adult\&ots=oISLwcg8_S\&sig=bsvT4 N51qUK1i1lASkWqLjWJ0eo.

Buitelaar, J. K., Van der Wees, M., Swaab-Barneveld, H., \& Van Der Gaag, R. J. (1999). Theory of mind and emotion-recognition functioning in autistic spectrum disorders and in psychiatric control and normal children. Development and Psychopathology, 11(1), 39-58.

Capps, L., Yirmiya, N., \& Sigman, M. (1992). Understanding of simple and complex emotions in non-retarded children with autism. Journal of Child Psychology and Psychiatry, 33(7), 1169-1182. doi: $10.1111 /$ j.1469-7610.1992.tb00936.x.

CDC. (2016). Facts about ASDs. Retrieved February 25, 2015, from http://www.cdc.gov/ncbddd/autism/facts.html.

Connor, K. M., Davidson, J. R. T., Churchill, L. E., Sherwood, A., Weisler, R. H., \& Foa, E. (2000). Psychometric properties of the social phobia inventory (SPIN): New self-rating scale. The British Journal of Psychiatry, 176(4), 379-386. doi:10.1192/bjp.176.4.379.

Constantino, J. N., Davis, S. A., Todd, R. D., Schindler, M. K., Gross, M. M., Brophy, S. L., ... Reich, W., et al. (2003). Validation of a brief quantitative measure of autistic traits: Comparison of the social responsiveness scale with the autism diagnostic interview-revised. Journal of Autism and Developmental Disorders, 33(4), 427-433. doi:10.1023/A:1025014929212. 
Davis, M. H., \& Oathout, H. A. (1987). Maintenance of satisfaction in romantic relationships: Empathy and relational competence. Journal of

Personality and Social Psychology, 53(2), 397-410. doi:10.1037/00223514.53.2.397.

DiTommaso, E., \& Spinner, B. (1993). The development and initial validation of the social and emotional loneliness scale for adults (SELSA).

Personality and Individual Differences, 14(1), 127-134.

doi: 10.1016/0191-8869(93)90182-3.

Dotson, W. H., Leaf, J. B., Sheldon, J. B., \& Sherman, J. A. (2010). Group teaching of conversational skills to adolescents on the autism spectrum. Research in Autism Spectrum Disorders, 4(2), 199-209. doi: $10.1016 /$ j.rasd.2009.09.005.

Dziobek, I., Rogers, K., Fleck, S., Bahnemann, M., Heekeren, H. R., Wolf, O. T., \& Convit, A. (2008). Dissociation of cognitive and emotional empathy in adults with Asperger syndrome using the Multifaceted Empathy Test (MET). Journal of Autism and Developmental Disorders, 38(3), 464-473. doi:10.1007/s10803-007-0486-x.

Farley, M. A., McMahon, W. M., Fombonne, E., Jenson, W. R., Miller, J., Gardner, M., ... Ritvo, R. A., et al. (2009). Twenty-year outcome for individuals with autism and average or near-average cognitive abilities. Autism Research, 2(2), 109-118. doi: 10.1002/aur.69.CrossRefPubMedGoogle Scholar

Faul, F., Erdfelder, E., Buchner, A., \& Lang, A.-G. (2009). Statistical power analyses using $\mathrm{G}^{*}$ Power 3.1: Tests for correlation and regression analyses. Behavior Research Methods, 41(4), 1149-1160.

Frankel, F., Myatt, R., Sugar, C., Whitham, C., Gorospe, C. M., \& Laugeson, E. (2010). A randomized controlled study of parent-assisted children's friendship training with children having autism spectrum disorders. Journal of Autism and Developmental Disorders, 40(7), 827-842. doi:10.1007/s10803-009-0932-z.

Fresco, D. M., Coles, M. E., Heimberg, R. G., Liebowitz, M. R., Hami, S., Stein, M. B., \& Goetz, D. (2001). The Liebowitz Social Anxiety Scale: a comparison of the psychometric properties of self-report and clinicianadministered formats. Psychological Medicine, 31(06), 1025-1035.

Gantman, A., Kapp, S. K., Orenski, K., \& Laugeson, E. A. (2012). Social skills training for young adults with high-functioning autism spectrum disorders: A randomized controlled pilot study. Journal of Autism and Developmental Disorders, 42(6), 1094-1103. doi:10.1007/s10803011-1350-6.

Gillott, A., Furniss, F., \& Walter, A. (2001). Anxiety in high-functioning children with autism. Autism: The International Journal of Research and Practice, 5(3), 277-286. doi:10.1177/1362361301005003005. 
NOT THE PUBLISHED VERSION; this is the author's final, peer-reviewed manuscript. The published version may be accessed by following the link in the citation at the bottom of the page.

Golan, O., \& Baron-Cohen, S. (2006). Systemizing empathy: Teaching adults with Asperger syndrome or high-functioning autism to recognize complex emotions using interactive multimedia. Development and Psychopathology, 18(02), 591-617. doi: $10.1017 /$ S0954579406060305.

Gresham, F., \& Elliott, S. N. (2008). Social skills improvement system (SSIS) rating scales. Bloomington, MN: Pearson Assessments. Retrieved from http://www.strivetogether.org/sites/default/files/images/45a\%20Socia $1 \% 20$ Skills\%20Improvement\%20System.pdf.

Gresham, F. M., \& Elliott, S. N. (1990). Social skills rating system: Manual. Circle Pines: American Guidance Service.

Gresham, F. M., Elliott, S. N., \& Kettler, R. J. (2010). Base rates of social skills acquisition/performance deficits, strengths, and problem behaviors: An analysis of the social skills improvement system-rating scales. Psychological Assessment, 22(4), 809-815. doi: $10.1037 / a 0020255$.

Gresham, F. M., Elliott, S. N., Vance, M. J., \& Cook, C. R. (2011). Comparability of the social skills rating system to the social skills improvement system: Content and psychometric comparisons across elementary and secondary age levels. School Psychology Quarterly, 26(1), 27. doi:10.1037/a0022662.

Hadwin, J. A., Howlin, P., Baron-Cohen, S., Rutter, M., \& Lewis, V. (1998). Children with autism and Asperger syndrome: A guide for practitioners and carers. Retrieved from http://eu.wiley.com/cda/product/0,,0471983284\%7Crv\%7C2606,00.h tml.

Hewitt, C. E., Kumaravel, B., Dumville, J. C., \& Torgerson, D. J. (2010). Assessing the impact of attrition in randomized controlled trials. Journal of Clinical Epidemiology, 63(11), 1264-1270. doi:10.1016/j.jclinepi.2010.01.010.

Howlin, P. (2000). Outcome in adult life for more able individuals with autism or Asperger syndrome. Autism: The International Journal of Research and Practice, 4(1), 63-83.

Howlin, P., Goode, S., Hutton, J., \& Rutter, M. (2004). Adult outcome for children with autism. Journal of Child Psychology and Psychiatry, 45(2), 212-229. doi:10.1111/j.1469-7610.2004.00215.x.

IBM Corp. (2013). IBM SPSS Statistics for Windows (Version 22.0). Armonk, NY: IBM Corp.

Kaufman, A. S., \& Kaufman, N. L. (2004). Kaufman brief intelligence test. Hoboken, NJ: Wiley Online Library. Retrieved from http://onlinelibrary.wiley.com/doi/10.1002/9781118660584.ese1325/s ummary.

Journal of Autism and Developmental Disorders, Vol 46, No. 12 (December 2016): pg. 3739-3754. DOI. This article is (C) Springer and permission has been granted for this version to appear in e-Publications@Marquette. Springer does not grant permission for this article to be further copied/distributed or hosted elsewhere without the express permission from Springer. 
Kennett, J. (2002). Autism, empathy and moral agency. The Philosophical Quarterly, 52(208), 340-357. doi:10.1111/1467-9213.00272.

Kerns, C. M., \& Kendall, P. C. (2012). The presentation and classification of anxiety in autism spectrum disorder. Clinical Psychology: Science and Practice, 19(4), 323-347. doi:10.1111/cpsp.12009.

Kerns, C. M., Kendall, P. C., Berry, L., Souders, M. C., Franklin, M. E., Schultz, R. T., ... Herrington, J., et al. (2014). Traditional and atypical presentations of anxiety in youth with autism spectrum disorder. Journal of Autism and Developmental Disorders, 44(11), 2851-2861. doi:10.1007/s10803-014-2141-7.

Laugeson, E. A., Frankel, F., Mogil, C., \& Dillon, A. R. (2009). Parent-assisted social skills training to improve friendships in teens with autism spectrum disorders. Journal of Autism and Developmental Disorders, 39(4), 596-606. doi:10.1007/s10803-008-0664-5.

Laugeson, E. A., Gantman, A., Kapp, S. K., Orenski, K., \& Ellingsen, R. (2015). A randomized controlled trial to improve social skills in young adults with autism spectrum disorder: The UCLA PEERS $®$ Program. Journal of Autism and Developmental Disorders, 45(12), 3978-3989. doi: 10.1007/s10803-015-2504-8.

Laugeson, E. A. (in press). The PEERS treatment manual for young adults with autism spectrum disorder: Evidence-based social skills training. New York, NY: Routledge.

Lawrence, E. J., Shaw, P., Baker, D., Baron-Cohen, S., \& David, A. S. (2004). Measuring empathy: Reliability and validity of the empathy quotient. Psychological Medicine, 34(05), 911-920. doi: $10.1017 /$ S0033291703001624.

Lever, A. G., \& Geurts, H. M. (2016). Psychiatric co-occurring symptoms and disorders in young, middle-aged, and older adults with autism spectrum disorder. Journal of Autism and Developmental Disorders, 46(6), 1916-1930.

Locke, J., Ishijima, E. H., Kasari, C., \& London, N. (2010). Loneliness, friendship quality and the social networks of adolescents with highfunctioning autism in an inclusive school setting. Journal of Research in Special Educational Needs, 10(2), 74-81. doi:10.1111/j.14713802.2010.01148.x.

Lord, C., Risi, S., Lambrecht, L., Cook, E. H. Jr., Leventhal, B. L., DiLavore, P. C., ... Rutter, M., et al. (2000). The autism diagnostic observation schedule-generic: A standard measure of social and communication deficits associated with the spectrum of autism. Journal of Autism and Developmental Disorders, 30(3), 205-223.

doi: $10.1023 / A: 1005592401947$. 
NOT THE PUBLISHED VERSION; this is the author's final, peer-reviewed manuscript. The published version may be accessed by following the link in the citation at the bottom of the page.

Lord, C., Rutter, M., DiLavore, P. C., \& Risi, S. (2002). Autism diagnostic observation schedule: ADOS: manual. Los Angeles, CA: Western Psychological Services.

Maddox, B. B., \& White, S. W. (2015). Comorbid social anxiety disorder in adults with autism spectrum disorder. Journal of Autism and Developmental Disorders, 45(12), 3949-3960. doi:10.1007/s10803015-2531-5.

Mathias, A., Steiger A. E. (2014). Empathy development in adolescence predicts social competencies in adulthood. Journal of Personality, 83(2), 229-241. doi:10.1111/jopy.12098.

McNeely, B. L., \& Meglino, B. M. (1994). The role of dispositional and situational antecedents in prosocial organizational behavior: An examination of the intended beneficiaries of prosocial behavior. Journal of Applied Psychology, 79(6), 836-844. doi:10.1037/00219010.79.6.836.

Palmen, A., Didden, R., \& Arts, M. (2008). Improving question asking in highfunctioning adolescents with autism spectrum disorders: Effectiveness of small-group training. Autism: The International Journal of Research and Practice, 12(1), 83-98. doi:10.1177/1362361307085265.

Palmen, A., Didden, R., \& Lang, R. (2012). A systematic review of behavioral intervention research on adaptive skill building in high-functioning young adults with autism spectrum disorder. Research in Autism Spectrum Disorders, 6(2), 602-617. doi:10.1016/j.rasd.2011.10.001.

Ranta, K., Kaltiala-Heino, R., Koivisto, A.-M., Tuomisto, M. T., Pelkonen, M., \& Marttunen, M. (2007). Age and gender differences in social anxiety symptoms during adolescence: The Social Phobia Inventory (SPIN) as a measure. Psychiatry Research, 153(3), 261-270. doi:10.1016/j.psychres.2006.12.006.

Reichow, B., Steiner, A. M., \& Volkmar, F. (2013). Cochrane Review: Social skills groups for people aged 6 to 21 with autism spectrum disorders (ASD). Evidence-Based Child Health: A Cochrane Review Journal, 8(2), 266-315. doi:10.1002/ebch.1903.

Schohl, K. A., Van Hecke, A. V., Carson, A. M., Dolan, B., Karst, J., Stevens, S. (2014). A replication and extension of the PEERS intervention: Examining effects on social skills and social anxiety in adolescents with autism spectrum disorders. Journal of Autism and Developmental Disorders, 44(3), 532-545. doi:10.1007/s10803-013-1900-1.

Schonert-Reichl, K. A. (1993). Empathy and social relationships in adolescents with behavioral disorders. Behavioral Disorders, 18(3), 189-204.

Seltzer, M. M., Shattuck, P., Abbeduto, L., \& Greenberg, J. S. (2004). Trajectory of development in adolescents and adults with autism.

Journal of Autism and Developmental Disorders, Vol 46, No. 12 (December 2016): pg. 3739-3754. DOI. This article is (C) Springer and permission has been granted for this version to appear in e-Publications@Marquette. Springer does not grant permission for this article to be further copied/distributed or hosted elsewhere without the express permission from Springer. 
NOT THE PUBLISHED VERSION; this is the author's final, peer-reviewed manuscript. The published version may be accessed by following the link in the citation at the bottom of the page.

Mental Retardation and Developmental Disabilities Research Reviews, 10(4), 234-247. doi:10.1002/mrdd.20038.

Stanger, C., \& Lewis, M. (1993). Agreement among parents, teachers, and children on internalizing and externalizing behavior problems. Journal of Clinical Child Psychology, 22(1), 107-116. doi:10.1207/s15374424jccp2201_11.

Tabachnick, B. G., \& Fidell, L. S. (2013). Using multivariate statistics. Retrieved from https://www.ulb.tu-darmstadt.de/tocs/135813948.pdf.

Van Steensel, F. J., Bögels, S. M., \& Perrin, S. (2011). Anxiety disorders in children and adolescents with autistic spectrum disorders: A metaanalysis. Clinical Child and Family Psychology Review, 14, 302-317.

Warren, Z., McPheeters, M. L., Sathe, N., Foss-Feig, J. H., Glasser, A., \& Veenstra-VanderWeele, J. (2011). A systematic review of early intensive intervention for autism spectrum disorders. Pediatrics, 127(5), e1303-e1311. doi:10.1542/peds.2011-0426.

White, S. W., Keonig, K., \& Scahill, L. (2007). Social skills development in children with autism spectrum disorders: A review of the intervention research. Journal of Autism and Developmental Disorders, 37(10), 1858-1868. doi:10.1007/s10803-006-0320-x.

White, S. W., Oswald, D., Ollendick, T., \& Scahill, L. (2009). Anxiety in children and adolescents with autism spectrum disorders. Clinical Psychology Review, 29(3), 216-229. doi:10.1016/j.cpr.2009.01.003.

White, S. W., \& Roberson-Nay, R. (2009). Anxiety, social deficits, and Ioneliness in youth with autism spectrum disorders. Journal of Autism and Developmental Disorders, 39(7), 1006-1013. doi: $10.1007 / \mathrm{s} 10803-009-0713-8$.

Wright, C. C., \& Sim, J. (2003). Intention-to-treat approach to data from randomized controlled trials: A sensitivity analysis. Journal of Clinical Epidemiology, 56(9), 833-842. doi:10.1016/S0895-4356(03)00155-0.

Yoo, H.-J., Bahn, G., Cho, I.-H., Kim, E.-K., Kim, J.-H., Min, J.-W., ... others, et al. (2014). A randomized controlled trial of the Korean version of the PEERS $®$ parent-assisted social skills training program for teens with ASD. Autism Research, 7(1), 145-161. doi:10.1002/aur.1354. Zablotsky, B., Black, L., Maenner, M., Schieve, L., \& Blumberg, S. (2015). Estimated prevalence of autism and other developmental disabilities following questionnaire changes in the 2014 National Health Interview Survey (Report No. 87). Hyattsville, MD: National Center for Health Statistics. Retrieved from http://www.cdc.gov/nchs/data/nhsr/nhsr087.pdf.

Journal of Autism and Developmental Disorders, Vol 46, No. 12 (December 2016): pg. 3739-3754. DOI. This article is (C) Springer and permission has been granted for this version to appear in e-Publications@Marquette. Springer does not grant permission for this article to be further copied/distributed or hosted elsewhere without the express permission from Springer. 